\section{Poor public health knowledge about glaucoma: fact or fiction?}

H Baker $^{1}$, SN Cousens ${ }^{2}$ and IE Murdoch ${ }^{1,3}$

\begin{abstract}
Purpose To document public awareness and knowledge of glaucoma.

Patients and methods The study used health knowledge questionnaires. (a) A short, structured telephone interview was performed with a nationally representative sample of 1009 people. (b) A more detailed questionnaire was administered in two contrasting regions by telephone (500 interviews from the Isle of Wight and 226 interviews from Ealing) or face to face (300 interviews from Ealing). Results Between 71 and $93 \%$ of those interviewed by telephone reported having heard of glaucoma, compared with only $23 \%$ of those interviewed face to face in Ealing. Of those who reported having heard of glaucoma, over $80 \%$ had at least some knowledge about the disease.

Conclusion This is the first study of public awareness of glaucoma across the UK. We found a relatively high level of awareness and knowledge of glaucoma in the general UK population, but identified at least one pocket of poor knowledge in a specific subpopulation.

Eye (2010) 24, 653-657; doi:10.1038/eye.2009.155; published online 26 June 2009
\end{abstract}

Keywords: glaucoma; knowledge; public

\section{Introduction}

Estimates suggest that glaucoma affects some 67 million people worldwide, ${ }^{1}$ and it is one of the major causes of preventable blindness in the UK. ${ }^{2}$ Owing to its slow progression, individuals do not notice any problems in the early stages of the disease. In developed countries, only half of all glaucoma sufferers are diagnosed and receiving treatment at any given time. ${ }^{3,4}$

In the UK, over $95 \%$ of referrals for suspected glaucoma are by high street optometrists among individuals attending for refraction. ${ }^{5}$ Not infrequently, patients are blind or severely handicapped by the time of referral. Grant and Burke $^{6}$ estimated that one-third of the patients who were blind from glaucoma had become so before they sought medical attention. This finding is consistent with other studies. ${ }^{7,8}$ Unfortunately, once damage has occurred to the optic nerve, it cannot be reversed; so early detection and treatment of the disease are important to preserve vision. ${ }^{6,9}$

It has been suggested that the phenomenon of late diagnosis could be due, in part, to low public awareness of glaucoma. Several studies outside the $\mathrm{UK}^{10,11}$ have reported poor knowledge of glaucoma (having heard of glaucoma and knowledge about glaucoma).

To date, public awareness and knowledge of glaucoma in the UK have not been investigated. This study aimed to address this gap.

\section{Materials and methods}

The study comprised of two components. In the first component, detailed interviews were performed with 500 individuals in the Isle of Wight and 526 individuals in Ealing. The interviews in the Isle of Wight and 226 interviews in Ealing were done by telephone. Studies in other areas including breast and ovarian cancer ${ }^{12}$ and sexual behaviour ${ }^{13,14}$ have used this method successfully. In some cases, it has been found that a telephone interview is more suitable because the remoteness between the interviewer and respondent can encourage greater honesty. ${ }^{15,16}$

However, it was noted that the telephone interview procedure in Ealing yielded very few respondents from ethnic minorities despite the availability of Hindi-speaking interviewers. To access ethnic minorities in Ealing, 300 face-toface interviews were performed in individuals' homes and places of worship in their normal spoken language (Hindi, Gujarati or Punjabi).
${ }^{1}$ Institute of Ophthalmology, University College London, London, UK

${ }^{2}$ Department of Epidemiology and Population Health, Infectious Disease Epidemiology Unit, London School of Hygiene and Tropical Medicine, London, UK

${ }^{3}$ Glaucoma Department, Moorfields Eye Hospital, London, UK

Correspondence: H Baker, Institute of Ophthalmology, University College London, Nov-43, Bath Street, London EC1V 9EL, UK

Tel: + 4402076086896 ;

Fax: + 4402072503207 .

E-mail: h.baker@

ucl.ac.uk

Received: 22 January 2009 Accepted in revised form: 28 May 2009

Published online: 26 June 2009

Funding source: This survey was kindly funded by the Guide Dogs for the Blind Association. The grant was unrestricted and investigators were given complete freedom in the design, analysis and interpretation of the data.

This work has been presented at the 8th General Assembly of the International Agency for the Prevention of Blindness in August 2008. 
For the telephone interviews, a sample of landline telephone numbers was supplied by Survey Sampling Incorporated using their Equal Probability of Selection Method (EPSEM). The EPSEM database has been created from Oftel data, using the basic 'building blocks' from which BT and all telephone providers generate telephone numbers. This means that all numbers have an equal probability of selection, and ex-directory and cable telephone numbers are included.

The face-to-face interviewees were identified by the interviewer attending all places of worship. These are located all around the borough and were a good place to reach our target population. Participants were also selected by knocking on peoples' doors in streets that had been selected before the interviews took place to ensure the whole area was covered.

All methods used quota sampling by age group and all participants reported being resident within the study area.

In the light of the findings from the Isle and Wight and Ealing, we then performed a national telephone survey of 1009 individuals in English using the same random telephone dialling methods.

In addition to the questions to determine social class grading (NSEC), two questions were asked:

1. Have you heard of glaucoma?

2. What do you think glaucoma is? Just tell me in your own words.

\section{Questionnaire}

The questionnaire was designed in conjunction with British Marketing Research Bureau (BMRB), specialists in the field, and in liaison with researchers with experience in the area of glaucoma health knowledge. ${ }^{10,17}$ Two agencies (BMRB and Ethnic Media Focus) carried out the interviews. Care was taken in the wording of questions to avoid leading questions and in their ordering to avoid questions, which could inform subsequent responses. The questionnaire was piloted and modified in the light of that experience. Interviews carried out in languages other than English used 'local' terms for glaucoma where appropriate. The same questionnaire with a standard introduction was used for all interviews excluding the national sample. The questionnaire started with general health questions that included eye-specific topics (eg medical checks in last 12 months, diseases heard of). Open questions on glaucoma and cataract were then followed by more detailed questions. Glaucoma knowledge was assessed by 14 true/false questions. The national sample was an omnibus survey carried out by the BMRB, which was standardised.
The open responses were 'scored', being awarded +1 for a correct point concerning the disease and -1 for an incorrect point concerning the disease. Individuals with a score below 1 were classified as having no knowledge, those with a score of 1 were classified as having minimal knowledge and those with a score $>1$ as having some knowledge. An example of a correct answer would be 'build up of pressure in the eye', 'can lead to blindness' or 'can be treated with eye drops'. Incorrect responses include 'something to do with your blood', 'to do with poor diet' or 'cannot be treated'.

This study had ethical approval from Moorfields Eye Hospital Ethical Committee, Isle of Wight, Portsmouth and South East Hampshire Health Authority Ethical committee and Ealing Ethical committee.

\section{Results}

A total of 2071 interviews were completed. For the telephone interviews, we had 2.5 refusals for every acceptance compared with 2.3 refusals for every face-toface interview. The demographic and socio-economic characteristics of four samples are shown in Table 1. There were similar numbers of male and females. The national sample included individuals aged $<35$ years, but did not include anyone in the 'routine', 'semi-routine' or unemployed groups.

Of the 2071 individuals interviewed, 1531 (74\%) reported having heard of glaucoma. The most striking observation with respect to these responses was the major difference in the proportion having heard of glaucoma between the Ealing face-to-face interviews (23\%) and the other groups (78\% or greater) (Table 1$)$. Eleven regions were sampled in the national sample. The proportion who had heard of glaucoma between regions ranged from 71 to $86 \%\left(\chi^{2}=25.8 P=0.17\right)$. In unadjusted analyses, females $(P=0.001)$ aged over 34 years $(P=0.02)$ and higher social class $(P<0.001)$ were all associated with an increased probability of having heard of glaucoma.

\section{Validity}

In the detailed interviews, those who reported having never heard of glaucoma or cataract were asked a second time if they were sure. Concordance of responses was $96 \%$ for glaucoma and $94 \%$ for cataract. The amount of knowledge professed in seven individuals who only answered positively for having heard of glaucoma on the second asking was very low suggesting good repeatability. The validity of responses is supported by the fact that none of the 120 who said they had only heard of the name glaucoma gave a response in the 
Table 1 Distribution by sex, age, area and NSECa for having heard of glaucoma

\begin{tabular}{|c|c|c|c|c|c|}
\hline & IoW telephone & Ealing telephone & National survey & Ealing face-to-face & Total \\
\hline \multicolumn{6}{|l|}{$\operatorname{Sex}$} \\
\hline Male & $205 / 226(91 \%)$ & $83 / 115(72 \%)$ & $364 / 477(76 \%)$ & $40 / 165(24 \%)$ & $692 / 983(70 \%)$ \\
\hline Female & $260 / 274(95 \%)$ & $123 / 147(84 \%)$ & $427 / 532(80 \%)$ & 29/135 (21\%) & $839 / 1088(77 \%)$ \\
\hline \multicolumn{6}{|l|}{ Age (years) } \\
\hline $0-34$ & - & - & $170 / 258(66 \%)$ & - & $170 / 258(66 \%)$ \\
\hline $35-44$ & $60 / 67(90 \%)$ & $48 / 57(84 \%)$ & $181 / 227(80 \%)$ & $6 / 48(13 \%)$ & $295 / 399(74 \%)$ \\
\hline $45-54$ & $112 / 114(98 \%)$ & $59 / 78(76 \%)$ & $137 / 158(87 \%)$ & $36 / 94(38 \%)$ & $344 / 444(77 \%)$ \\
\hline $55-64$ & $131 / 140(94 \%)$ & $33 / 44(75 \%)$ & $130 / 159(82 \%)$ & $17 / 75(23 \%)$ & $311 / 418(74 \%)$ \\
\hline $65+$ & $161 / 178(90 \%)$ & $61 / 78(78 \%)$ & $162 / 193(84 \%)$ & $10 / 83(12 \%)$ & $394 / 532(74 \%)$ \\
\hline \multicolumn{6}{|l|}{ NSECa } \\
\hline Higher professional & $46 / 47(98 \%)$ & $17 / 19(89 \%)$ & $174 / 199(87 \%)$ & $7 / 14(50 \%)$ & $244 / 279(87 \%)$ \\
\hline Lower professional & 101/108 (94\%) & $29 / 35(83 \%)$ & $264 / 329(80 \%)$ & 7/19 (37\%) & $401 / 491(82 \%)$ \\
\hline Intermediate & $58 / 61(95 \%)$ & $19 / 23(83 \%)$ & 148/191 (77\%) & $10 / 23(43 \%)$ & $235 / 298(79 \%)$ \\
\hline Small employers & $21 / 22(95 \%)$ & $1 / 1(100 \%)$ & $79 / 114(69 \%)$ & $8 / 36(22 \%)$ & $109 / 173(63 \%)$ \\
\hline Technical & $28 / 30(93 \%)$ & $13 / 14(93 \%)$ & $104 / 143(73 \%)$ & $9 / 24(38 \%)$ & $154 / 211(73 \%)$ \\
\hline Semi-routine & $54 / 61(89 \%)$ & $30 / 40(75 \%)$ & - & $10 / 50(20 \%)$ & $94 / 151(62 \%)$ \\
\hline Routine & $54 / 58(93 \%)$ & $10 / 18(56 \%)$ & - & $15 / 98(15 \%)$ & $79 / 174(45 \%)$ \\
\hline Unemployed & $3 / 4(75 \%)$ & $5 / 12(42 \%)$ & - & $0 / 20(0 \%)$ & $8 / 36(22 \%)$ \\
\hline
\end{tabular}

section, in which they were asked to describe it. A similar finding was true for cataract.

A logistic regression model was then constructed with 'heard of glaucoma' as the outcome (Table 2). The results are consistent with those of the crude analysis presented in Table 1.

Respondent's knowledge of glaucoma was assessed in two ways. First, those interviewed were asked how much they considered they knew about glaucoma. Second, an open-ended question was asked 'What do you think glaucoma is? Just tell me in your own words'. Not all those who reported having heard of glaucoma responded to this question $(1362 / 1531(89 \%))$. Of those who responded, $86 \%$ gave an answer that included some reference to the eye. Table 3 shows the results of these two assessments.

\section{Discussion}

The first major finding of this study is that more people have heard of glaucoma than suggested by patient and professional perceptions. ${ }^{18-20}$ However, we found much lower awareness in the face-to-face interviews in an ethnic minority population. One possible explanation for our findings is that the telephone sampling procedure resulted in bias towards a more aware population. Although the low response rate (about one-third) provides substantial scope for selection bias, it is not lower than that reported for other telephone surveys. ${ }^{21}$ In addition, our results agree with other studies in developed countries. ${ }^{10,11,17,22}$
Table 2 Odds ratios for the associations between the outcome 'having heard of glaucoma' and sex, age, sampling source and NSECa

\begin{tabular}{lcc}
\hline Variable & $\begin{array}{c}\text { Adjusted odds ratios } \\
\text { (95\% confidence interval) }\end{array}$ & P-value \\
\hline Sex & & \\
$\quad$ Female & 1.0 & 0.02 \\
Male & $0.75(0.58,0.96)$ & \\
& & \\
Age (years) & 1.0 & \\
$<35$ & $2.10(1.41,3.13)$ & \\
35-44 & $4.26(2.71,6.70)$ & $<0.0001$ \\
45-54 & $2.43(1.59,3.72)$ & \\
55-64 & $2.30(1.52,3.49)$ & \\
65+ & & \\
Source & 1.0 & \\
IoW telephone & $0.25(0.14,0.44)$ & \\
Ealing telephone & $0.23(0.14,0.38)$ & \\
National telephone & $0.03(0.02,0.04)$ & \\
Ealing face-to-face & & \\
NSECa & 1.0 & \\
Higher managerial & $0.62(0.37,0.98)$ & \\
Lower managerial & $0.55(0.34,0.90)$ & \\
Intermediate & $0.33(0.20,0.56)$ & \\
Small employers & $0.40(0.24,0.67)$ & \\
Lower supervisory & $0.24(0.13,0.46)$ & \\
Semi-routine & $0.18(0.10,0.34)$ & \\
Routine & $0.05(0.02,0.14)$ & \\
Unemployed & & \\
\hline & & \\
\end{tabular}

It could be that the difference in awareness of glaucoma between the face-to-face interviewees and the telephone interviewees does not simply show selection 
Table 3 Level of knowledge about glaucoma

\begin{tabular}{|c|c|c|c|c|c|}
\hline Knowledge & IoW telephone & Ealing telephone & Ealing face to -face & Whole country ${ }^{\mathrm{a}}$ & Total \\
\hline \multicolumn{6}{|c|}{ Own assessment } \\
\hline Nil & $96(20 \%)$ & $3(1 \%)$ & $21(31 \%)$ & - & $120(15 \%)$ \\
\hline Small & $145(30 \%)$ & $65(29 \%)$ & $16(24 \%)$ & - & $236(30 \%)$ \\
\hline Some & $241(50 \%)$ & $158(70 \%)$ & $30(45 \%)$ & - & $429(55 \%)$ \\
\hline \multicolumn{6}{|c|}{ Open question responses } \\
\hline Nil & $96(25 \%)$ & $50(32 \%)$ & $2(4 \%)$ & $107(14 \%)$ & $255(18 \%)$ \\
\hline Small & $160(42 \%)$ & $64(41 \%)$ & $11(24 \%)$ & $460(58 \%)$ & $695(50 \%)$ \\
\hline Some & $129(34 \%)$ & $44(28 \%)$ & $33(72 \%)$ & $224(28 \%)$ & $430(31 \%)$ \\
\hline
\end{tabular}

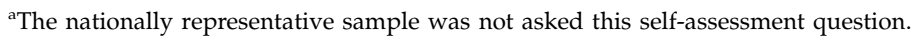

NB: Fewer answered the open-ended question.

bias in the two different recruitment methods, but could reflect an underlying difference. This is supported by the fact that other studies in developed countries using faceto-face interviews had similar results to those found in our telephone sample.

In addition to a large proportion having heard of glaucoma, over $80 \%$ of those who had heard of the disease reported some knowledge about it. This profession of knowledge was supported by the proportion of people who showed correct knowledge in response to the open-ended question.

The low level of awareness in the face-to-face interviews in Ealing is important in highlighting a potential deficiency of random telephone interviews. In Ealing, the telephone sampling method found the same level of awareness of glaucoma as the national sample (78\%). The face-to-face interviews found $23 \%$ awareness. It can be hypothesized that the telephone is more likely to be answered by an English-speaking member of the family who is more informed, or not answered at all. This result is important for the interpretation of other studies, in which sampling was undertaken by random digit dialling. Ethnic or other minorities may not be properly represented. This phenomenon has not been reported earlier. $^{23,24}$

In Ealing, it was in the Indian population in which we observed a low awareness of glaucoma. Although faceto-face interviewers used colloquial terms for the word glaucoma for clarity when required, it is possible that this reflects the issues of translation rather than poor understanding of glaucoma. However, we think that this is unlikely, as in the same questionnaire participants were asked if they had heard of cataract, to which $99 \%$ of the population answered yes and diabetic retinopathy, of which $72 \%$ had heard.

The areas of low awareness are a concern, and in the case of the ethnic minorities in Ealing, we are addressing this with public health campaign to see if awareness about glaucoma can be improved. Interestingly, those that were aware of glaucoma in this subgroup had a high degree of knowledge of glaucoma.

The higher level of awareness contrasts with the findings from other countries, ${ }^{10,22}$ and from the earlier qualitative studies. ${ }^{18,20}$ This observation argues against a lack of awareness being the main reason why only $50 \%$ of glaucoma cases have been diagnosed at any one time.

Awareness of glaucoma was slightly higher among females than males (77 vs $71 \%$ ). This finding is consistent with other studies. ${ }^{10,25}$ Awareness was lower among those aged $<35$ years. The work of Michielutte et $\mathrm{l}^{25}$ also found younger people to be less knowledgeable.

People from higher social class were more aware, although there is a bias in the national sample; no individuals from semi-routine, routine or unemployed were sampled. This is likely to mean that we have a slight over estimate of numbers who have heard of glaucoma in the national sample. However, the results from the other telephone interviews include these grades and show similar proportions having heard of glaucoma. The Whitehall study ${ }^{26}$ found that lower social classes had a higher incidence of disease and discussed aspects, such as lifestyle, environmental and occupational exposures, including the psychosocial to consider as factors contributing to this. If we assume that awareness leads to an increased chance of diagnosis, then it is more likely for the lower social classes to be undiagnosed in the community going blind from the disease. This is consistent with Fraser et al, ${ }^{27}$ who have shown that people in lower social classes are more at risk of going blind from glaucoma because of late presentation.

\section{Conclusions}

It appears that it would be wrong to assume that people in the UK have not heard of glaucoma. Among those responding to our study, not only had the majority of older people heard of the disease, but they also had a degree of knowledge about the disease. Why then are 
only $50 \%$ of glaucoma suffers diagnosed and receiving therapy? The RNIB have reported one of the barriers to eyes tests in older people to be lack of awareness. ${ }^{28}$ In the light of our findings, this requires further investigation.

This is the first study of public health knowledge of glaucoma across the UK. This study observed a higher than anticipated level of awareness and knowledge of glaucoma and highlighted a limitation of a telephone survey approach. In our case, a telephone survey missed a pocket of low awareness.

\section{References}

1 Quigley HA. Number of people with glaucoma worldwide. Br J Ophthalmol 1996; 80(5): 389-393.

2 Evans JR, Fletcher AE, Wormald RP. Causes of visual impairment in people aged 75 years and older in Britain: an add-on study to the MRC Trial of Assessment and Management of Older People in the Community. $\mathrm{Br} J$ Ophthalmol 2004; 88(3): 365-370.

3 Sommer A, Tielsch JM, Katz J, Quigley HA, Gottsch JD, Javitt JC et al. Racial differences in the cause-specific prevalence of blindness in east Baltimore. $N$ Engl J Med 1991; 325(20): 1412-1417.

4 Tielsch JM, Sommer A, Katz J, Royall RM, Quigley HA, Javitt J. Racial variations in the prevalence of primary openangle glaucoma. The Baltimore Eye Survey. JAMA 1991; 266(3): 369-374.

5 Bell RW, O'Brien C. Accuracy of referral to a glaucoma clinic. Ophthalmic Physiol Opt 1997; 17(1): 7-11.

6 Grant WM, Burke Jr JF. Why do some people go blind from glaucoma? Ophthalmology 1982; 89(9): 991-998.

7 Sheldrick JH, Ng C, Austin DJ, Rosenthal AR. An analysis of referral routes and diagnostic accuracy in cases of suspected glaucoma. Ophthalmic Epidemiol 1994; 1(1): 31-39.

8 Coffey M, Reidy A, Wormald R, Xian WX, Wright L, Courtney P. Prevalence of glaucoma in the west of Ireland. Br J Ophthalmol 1993; 77(1): 17-21.

9 Vogel R, Crick RP, Newson RB, Shipley M, Blackmore H, Bulpitt CJ. Association between intraocular pressure and loss of visual field in chronic simple glaucoma. $\mathrm{Br} \mathrm{J}$ Ophthalmol 1990; 74(1): 3-6.

10 Livingston PM, Lee SE, De Paola C, Carson CA, Guest CS, Taylor HR et al. Knowledge of glaucoma, and its relationship to self-care practices, in a population sample. Aust NZ J Ophthalmol 1995; 23(1): 37-41.

11 Pfeiffer N, Krieglstein GK, Wellek S. Knowledge about glaucoma in the unselected population: a German survey. J Glaucoma 2002; 11(5): 458-463.
12 Hallowell N, Murton F, Statham H, Green JM, Richards MP. Women's need for information before attending genetic counselling for familial breast or ovarian cancer: a questionnaire, interview, and observational study. BMJ 1997; 314(7076): 281-283.

13 Beckman LJ, Harvey SM, Thorburn S, Maher JE, Burns KL. Women's acceptance of the diaphragm: the role of relationship factors. J Sex Res 2006; 43(4): 297-306.

14 Patrick ME, Maggs JL, Abar CC. Reasons to have sex, personal goals, and sexual behavior during the transition to college. J Sex Res 2007; 44(3): 240-249.

15 Sturges J, Hanrahan K. Comparing telephone and face-toface qualitative interviewing a research note. Qualitative Res 2004; 4(1): 107-118.

16 Fenig S, Levav I, Kohn R, Yelin N. Telephone vs face-to-face interviewing in a community psychiatric survey. Am J Public Health 1993; 83(6): 896-898.

17 Attebo K, Mitchell P, Cumming R, Smith W. Knowledge and beliefs about common eye diseases. Aust NZ J Ophthalmol 1997; 25(4): 283-287.

18 Burns J, Barrett G, Murdoch I. The experiences of patients with suspect glaucoma. Ophthalmic Nurs 2001; 5(3): 8-11.

19 Patel D, Baker H, Murdoch I. Barriers to uptake of available ophthalmic services among the Asian community in Ealing. Health Educ J 2006; 65(3): 267-276.

20 Green J, Siddall H, Murdoch I. Learning to live with glaucoma: a qualitative study of diagnosis and the impact of sight loss. Soc Sci Med 2002; 55(2): 257-267.

21 Nicolaas G, Lynn P. Random-digit dialling in the UK: viability revisited. J $R$ Stat Soc [Ser A] 2002; 165(Part 2): 297-316.

22 Lau JT, Lee V, Fan D, Lau M, Michon J. Knowledge about cataract, glaucoma, and age related macular degeneration in the Hong Kong Chinese population. Br J Ophthalmol 2002; 86(10): 1080-1084.

23 Newman WL. Survey research. In: Newman WL (ed.) Social Research Methods: Qualitative and Quantitative Approaches. 5th edn. USA: Allyn and Bacon, 2003, pp 289-290.

24 Nicolaas G. Sampling Issues for Telephone Surveys in Scotland 2004 [cited;www.bioss.ac.uk/staff/admin/rsse/2003-2004/ presentations/gerry_nicolaas.ppt. ].

25 Michielutte R, Diseker RA, Stafford CL, Carr P. Knowledge of diabetes and glaucoma in a rural North Carolina community. J Community Health 1984; 9(4): 269-284.

26 Marmot MG, McDowall ME. Mortality decline and widening social inequalities. Lancet 1986; 2(8501): 274-276.

27 Fraser S, Bunce C, Wormald R, Brunner E. Deprivation and late presentation of glaucoma: case-control study. BMJ 2001; 322(7287): 639-643.

28 RNIB. Older People and Eye Tests: Don't Let Age Rob You of Your Sight 2007 [cited 13/02/2008]; available from:www.rnib.org.uk/xpedio/groups/public/ documents/publicwebsite/public_oldereyereportp.pdf. 